\title{
English Medium Instruction in Higher Education: Teacher perspectives on professional development and certification.
}

Ernesto Macaro, Shuangmiao Han, Mustafa Akincioglu

\begin{abstract}
The growth in academic subjects taught through English, in non-Anglophone countries (English Medium Instruction, EMI) has been matched by growth in research into its desirability. Research has also indicated that EMI teachers need professional development (PD) to teach effectively. Although PD programmes are available, there is no consensus as to the competencies needed of an EMI teacher, nor of their certification. Our international survey explored teacher perspectives on proposed competencies in relation to the language challenges faced by EMI students and whether teachers believe certification is desirable. Teachers were keen to obtain certification at an international level thereby providing an aspect of programme quality assurance. However, they saw obstacles to obtaining competencies beyond merely a threshold level of their own general language proficiency.
\end{abstract}

Keywords: English medium instruction; teacher competence; certification; higher education.

\section{BACKGROUND: THE GROWTH AND CHALLENGES OF ENGLISH MEDIUM INSTRUCTION}

English Medium Instruction (EMI) in universities, is the practice of offering academic subjects such as Engineering, Business Studies or Medicine through the medium of English in countries where the first language (L1) of the majority of students is not English. Of course, given the ubiquitous nature of the phenomenon of EMI, its characteristics are not uniform, neither within-country nor between-countries. For example, there is evidence that English is not the only language used in EMI classrooms (e.g. Tarnopolsky \& Goodman, 2012, in the Ukraine; Lasagabaster, 2013, in Spain) but that the L1 is deployed to varying degrees when communication difficulties appear. There is also evidence that it is not an all or 
nothing situation: some academic subjects may be taught partly in English and partly in the L1 on different days or according to different components of the course or programme (Bolton \& Botha, 2015; Tong \& Shi, 2012), or according to the number of international students in the class (Kunioshi \& Nakakoji, 2018).

Despite the above different interpretations of what EMI might be, it is now well established that in Higher Education (HE) EMI is growing at a very fast rate and in most countries around the world (for a recent extensive review see Macaro et al. 2018). This growth is either documented in multinational surveys, as in the Europe-focused one by Wächter and Maiwarm (2014), or the Asia-based one by Fenton-Smith, Humphries and Walkinshaw (2017). It is also well documented by authors referring to individual countries, for example in Italy, (Guarda \& Helm, 2016) in Croatia (Margic \& Vodopija-Krstanovic, 2017), in Turkey (Sert, 2008; K1rkgöz, 2009), in China (Hu \& Li, 2017), and in Japan (Chapple, 2014; Rose \& McKinley, 2017).

Galloway et al. (2017) identify a number of drivers for this growth: increasing the international profile of the institution; increasing a university's income by attracting international students and/or compensating for falling domestic enrolment; enhancing home student mobility; improving students' English proficiency; using English as a 'neutral language' in contexts where the national language(s) is/are in dispute. In terms of student mobility, Coleman (2006) estimates that over seven million students are expected to be studying away from their home country by 2025 . This means that the position of English as the international lingua franca of academia is likely to be strengthened further. The phenomenon of EMI growth in HE (and also in secondary education) has raised concerns among commentators in terms of the impact this may have on the home language and culture (Jenkins, 2014; Kirkpatrick \& Liddicote, 2017) and also because of the inadequate levels of English language proficiency of students and faculty (British Council/TEPAV, 2015; Macaro, 
2018). Many research reports catalogue a list of concerns regarding teachers' feelings of inadequacy to switch from the L1 medium of instruction (MOI) to EMI. These feelings include a belief that they are not able to deliver content as efficiently as through their L1 MOI (Cho, 2012; K1liçkaya, 2000), that teaching through the L2 results in the use of more limited vocabulary and forms of expression (Vinke, 1995) and that EMI lectures are 'shallower and less precise' than lectures given through the L1 (Airey, 2011:44). Some research evidence (Jensen \& Thørgesen, 2011) suggests that younger EMI teachers see fewer challenges than older teachers and therefore respond more positively to increasing EMI provision, a finding these researchers suggest may be due to the former's greater command of English.

However a number of EMI teachers link these challenges not only to their own inadequate levels of English but also to that of their students (Kim \& Shin, 2014; Rogier, 2012). In Iraqi Kurdistan, Borg (2016) reported that the teachers surveyed estimated that almost $75 \%$ of their students had only beginner or elementary levels of English. Kırkgöz (2009a), in Turkey, provided evidence that the type of English being taught in EAP classes was not preparing students adequately for EMI programmes.

Thus, the question of teacher ability to teach through the medium of English may not simply be a question of their own level of English proficiency but of their general pedagogy, their understanding of the linguistic challenges EMI students face, and the interaction skills needed to communicate and ensure content learning with students whose own level of English may be insufficient. Interestingly, teachers in one study (Fortanet-Gómez, 2012) claimed that there was a sharp division between presenting a paper in English at a conference (76.9\% believed their English was up to a sufficient standard for this) and being able to teach through EMI where only 51.9\% felt they knew English well enough to do this effectively.

However, evidence suggests that not all teachers are aware of these additional language-related pedagogical skills needed (Dearden \& Macaro, 2016) but believe their 
subject can be taught with a relatively reduced linguistic repertoire, and with a tendency to believe that science and mathematics need less language for the explanation of difficult concepts than social sciences and humanities subjects. This would suggest that teachers of some subjects may feel less responsibility for attuning to the level of English of their students and less responsibility for helping students develop their linguistic proficiency in order to operate successfully in their academic subject. In other words, the notion of integrating the teaching of content and language which has recently gained traction in HE (Integrating Content and Language in Higher Education, ICLHE) following on from the European CLIL (Content and Language Integrated Learning) movement in secondary education, is not likely to find a receptive ear among certain sections of the HE teaching force worldwide (see Gimeno et al. 2010).

\section{BACKGROUND: TEACHER PREPARATION FOR EMI AND PROFESSIONAL DEVELOPMENT}

There is therefore a need to establish what kind of competencies an EMI teacher needs to teach effectively those students who have a range of linguistic levels and (in an increasingly international HE context) students from a range of cultural backgrounds, something which this study sought to begin to do. We define 'competencies' as the expert knowledge, understanding, and skills needed in order to effectively carry out (in our case) teaching an academic subject through the medium of English. Some researchers on teacher competetencies separate these into generic competencies and domain-specific competencies (Zlatkin-Troitschanskaia et al. 2017), a notion that is of relevance in developing teacher competencies in an EMI setting where, for example, general interaction skills are woven into discipline-specific interaction skills. Others also stress the importance of competencies based on student-centredness (Trigwell, 2001; Tigelaar et al., 2004) which in the light of the above discussion is also highly pertinent to EMI settings such as the ones explored in this study. 
Despite the growth of this relatively new way of teaching academic subjects in HE, and the challenges that it entails, there appear to be few universities offering some kind of certification providing evidence of a teacher's competence to teach through the medium of English (Cheng, 2017). Our own knowledge of the field suggests that there are a number of organizations offering pre-service teacher education and/or professional development (PD) for EMI teachers, and in various guises. For example the Certificate in EMI Skills course is a 40-hour online course offered by Cambridge Assessment, linked to the University of Cambridge (https://goo.gl/MWtCAF). According to the official website, 'the Certificate in EMI Skills helps higher education professionals to:

- Communicate more effectively in English with students and colleagues

- Use a range of language in different situations, from lectures and tutorials to conferences and online discussions

- Increase familiarity with a range of skills for delivering instruction in English.'

The University of Southampton offers a free 16-hour online 'EMI for Academics course' on a platform provided by Future Learn https://goo.gl/nfZyUB. It aims to equip teachers to teach in international contexts by increasing their English language skills and intercultural knowledge. The British Council offers a 35-hour face to face course entitled 'Academic Teaching Excellence' (https://goo.gl/N99TNY). Described as a 'foundation course', it aims to equip participants with the necessary competence to 'structure and deliver lectures in English effectively and confidently communicate with students whose first language is not English, use English language in supervision/discussion/small-group contexts'.

These then are the types of organizations that offer PD in EMI with participants not attached to the institution offering the programme. They would appear to be relatively baseline level introductions to the kinds of competencies that a major shift requires such as 
the one outlined above. We should also note that they tend to be offered by Anglophone institutions which may raise a number of issues for some academics already concerned about the spread of English as a lingua franca in HE (Canagarajah, 1999; Jenkins, 2014).

There are also a limited number of EMI universities that provide their own programmes of PD for their academics, and additionally for the purposes of the current paper, certification for them. For example the University of Copenhagen (Kling \&Staehr, 2012) offers certification through a Test of Oral English Proficiency of Academic Staff (TOEPAS) involving 20 minutes of simulated teaching in front of teacher-peers and judged on a scale which at the top end is defined as 'a highly articulate, well-educated native speaker of English' (Dimova \& Kling 2015). Although there is some reference to other pedagogical skills, a great deal of weight appears to be placed on the teacher's fluency, pronunciation, vocabulary, and grammar. The University of Freiburg, as reported in some detail in Dubow and Gundermann (2017:478), uses general language criteria which are by and large based on the CEFR (The Common European Framework of Reference for Languages) and on the IELTS (International Language Testing Service) and the teacher's competence to teach is based on an assessment of: 'their fluency in the language; their pronunciation; grammatical accuracy; lexical range and accuracy; and their ability to avoid the use of the L1' (p.479). Thus, it appears that a heavy emphasis is placed on a teacher's English language proficiency, possibly to the neglect of developing an EMI teacher's understanding of what an EMI student is faced with when learning an academic subject through a language they are not necessarily confident in and how students make progress with learning and using the L2 in an EMI context (Ball \& Lindsay, 2013). As Bradford (2018) argues in the context of Japan, there is often a misconception that a successful EMI programme depends on the teacher's English proficiency alone. In other words, a question remains as to whether a similar understanding of how learners learn, one often required of English as a Foreign Language teachers, should be 
required of EMI teachers. This would be a pre-requisite, we argue, if the goal of bringing about ICLHE is to be achieved.

To summarise, EMI in its various manifestations, but nonetheless as a substantially different way of teaching academic subjects in HE, is becoming ever more widespread in non-Anglophone countries and its implications and challenges are being recognized by teachers and researchers alike. Mechanisms for establishing teacher competence to teach through the medium of English are still in their very early stages and there is certainly no consensus at an international level of what the components of that competence should be. As Huang and Singh (2014) propose: 'the creation of a teaching quality framework is a crucial element in the toolkit required for judging or otherwise evaluating the performance, effectiveness and success of University EMI programmes' (p.363). Where teacher PD is offered it tends to be at either a single institutional level, or offered remotely by (mostly Anglophone) organizations with (presumably) little awareness of local factors. Given that EMI is largely being brought about by increasing internationalisation and student mobility, it is pertinent to ask the question whether some kind of international standard of EMI teacher competence is possible. Of course we acknowledge that in many countries PD at university level does not feature prominently when courses are taught in L1; there is often simply not a culture of expectations of university teacher pedagogical competencies. However we argue in this paper that regardless of the PD culture in individual countries, the additional challenges posed by EMI are highly likely to require PD. It is with this background that we sought to answer the following research questions at an international (multi-country) level.

\section{RESEARCH QUESTIONS}

(1) What evidence is there that EMI teachers in HE have taken part in PD courses in EMI? 
(2) To what extent do they consider teacher certification important, and at what level (institutional, national, international)?

(3) Do EMI teachers consider that teaching through English involves different competencies to L1 MOI, and what learning would they be prepared to undertake in order to obtain those competencies leading to certification?

\section{METHODOLOGY}

In order to try to obtain a broad multi-national perspective we adopted an essentially quantitative research design. The research instrument consisted of an online questionnaire for EMI teachers.

The online questionnaire could be accessed by potential respondents only if they obtained a website address which was part of one of the current authors' university learning platform. The website address was distributed via the network of connections around the world that the authors had.

The questionnaire was developed by adopting a grounded approach (Charmaz, 2008).We first carried out a number of interviews with EMI teachers in institutions where we had connections in order to get a sense of what they believed the issues were with regard to EMI PD and certification. A first draft of the questionnaire was then piloted to ensure that the English used was understandable, given that for a multi-country survey we could not provide multiple translations. The final version of the online questionnaire consisted of 25 closed Likert-type questions and some open-ended questions.

In the introduction, and following information about the purpose of the research and explanation of ethical/consent issues, we provided examples of what we meant by EMI and who qualified as an EMI teacher, as in the following two examples: 'Teaching Business Studies through the medium of English in Spain; Teaching Geography through the medium of English in China'. This explanation was in addition to a definition of EMI that made it 
clear that we were not including teachers of the English language as a subject. Despite these precautionary measures a number of respondents stated that they were indeed English language teachers. No less than 141 respondents therefore had to be eliminated from the sample. The fact that so many English language teachers felt they qualified to complete the questionnaire perhaps provides evidence of the still fuzzy nature of EMI as a concept. Of course, it is possible that they just wanted to give their opinions anyway, but these are beyond the scope of the current paper. Teachers of applied linguistics and translation studies however were included as even though there may be a language focus in these subjects, the primary objective is not to teach the English language. The many subjects reported were then categorised into six broad disciplines: Mathematical Sciences (MatSci), Natural Sciences (NatSci), Medical Sciences (MedSci), Social Sciences (SocSci), Humanities (Hums), Humanities with a Language Focus (Hums+LangFoc) (the last being those such as Translation Studies and Applied Linguistics). After further 'data cleaning' (ensuring, for example, that all teacher respondents were actually teaching through EMI or were just about to start) 463 EMI teachers remained. The numerical data was then entered onto SPSS version23.

The open-ended responses were analysed by two independent researchers to provide insights to the questions raised in the surveys and complement the quantitative analysis. They were first categorized under the three research questions above and then further categorised according to emerging issues. A Cronbach Alpha analysis of the questionnaire items related to EMI teacher attitudes to competencies and certification (i.e. not the biographical ones) produced a reliability measure of .76 which is acceptable given the diverse backgrounds of the respondents. Our 463 EMI teacher respondents were teaching in the following countries: Brazil, (5) 1.1\%; China (133) 29.8\%, Italy (30) 6.5\%, Japan (20) 4.3\%; Mexico, (34) 7.3\%; Spain (151) 32.6\%; Turkey (51) 11\%; Other (39) 8.4\%. We acknowledge as a limitation that 
these figures accurately reflect neither the size of the academic populations of these countries, nor the extent to which each country has embarked on the EMI educational route.

\section{FINDINGS}

Our first research question explored the extent to which respondents had taken part in PD in order to improve their ability to teach through the medium of English. As we can see from Table 1 nearly two-thirds of teachers had not taken part in PD and yet were teaching (85\%) or were about to start teaching (15\%) through EMI. Even for those who had participated in PD, respondents reported various forms and degrees of intensity. For example, one respondent claimed to have been 'trained for 4 months in Australia in 2004' while another mentioned that s/he had taken part in a '3-hour workshop'. There seemed to be no clear mandate between being asked to teach through English and PD programmes on offer. As articulated by one respondent: 'The Institute for Science of Education offers annually two or three training courses to teach content through English. But it is not mandatory to take them in order to teach in English.'

\section{INSERT TABLE 1 ABOUT HERE}

Our next question was about their beliefs concerning the importance of teacher certification. We therefore first asked EMI teachers whether their institution already offered its EMI teachers some kind of certification of competence to teach through EMI (see Table 2).

\section{INSERT TABLE 2 ABOUT HERE}

Only $23.4 \%$ of respondents reported awareness of the existence of EMI teachers' certification. For example, a respondent elaborated the situation in his/her university and national HE system as follows: 
YDS examination, which is a state-run English Test, is required to be taken by Turkish Council of Higher Education...There is a specific exam proposed by the university. Besides, there are several external certifications which are accepted, such as Proficiency Level by Cambridge University (which is the one I have). I am not sure which are the other certifications accepted but I know there are more. The university provides a certification through a test by the university itself. In addition, the university also certifies lecturers to teach in English as long as they have a $\mathrm{C} 1$ level certification in English by a legally recognized institution. I'm not sure about whether a $\mathrm{C} 1$ level is always sufficient for teaching in a given language.

However, nearly half of institutions were reported as not offering certification. Of note is the number of respondents who said they didn't know. As one teacher commented, 'As far as I know my university is neither certificating us nor asking us to have this special certification. My university has launched some EMI courses, and is encouraging more EMI courses, but has not used certification for EMI teachers yet.'

We then asked about the importance of certification. As we can see from Table 3 we asked this question at a personal, departmental, institutional and also at a global level. Overwhelmingly respondents answered positively with a very low number claiming that certification was not at all important and the pattern repeated itself fairly closely at all 'levels'. We further explored this issue by comparing the different age groups of respondents and their length of experience of teaching EMI. A one-way ANOVA with 'age group' as the independent variable produced no significant differences. However, a one-way ANOVA with 'experience group' (just starting EMI; less than 5 years; 5-10 years; more than 10 years) as independent variable produced two significant differences: (1) those just starting ( $M=2.61)$ considered certification important at a personal level $(\mathrm{F}=5.31 ; \mathrm{df}=427 ; \mathrm{p}<.001)$ than those who had been teaching it for 10 years or more $(M=1.9)$; (2) at a departmental level those with less than 5 years EMI experience $(\mathrm{M}=2.5)$ considered it more important $(\mathrm{F}=3.01$; 
$\mathrm{df}=424 ; \mathrm{p}<.05)$ than those who had been teaching it for 10 years or more $(\mathrm{M}=2.0)$. We return to these findings in our discussion.

\section{INSERT TABLE 3 ABOUT HERE}

Part of our operationalising of research question 3 considered the extent to which teaching through English involved different or additional competencies. We therefore asked whether they believed teaching had to change in an EMI context. Overwhelmingly responses were affirmative: yes $=63.5 \%$, no $=14.5 \%$, I'm not sure $=21 \%$. In the 'open-ended' questions, many teachers emphasized the importance of changing their pedagogy when it comes to EMI rather than simply improving their level of English. In their opinion, the necessity could be attributed to many factors, such as the language difference (for example, vocabulary in different content subjects) and teachers' and (particularly) students' English proficiency. As articulated by one respondent:

The teacher needs to adapt to students' proficiency. When teaching in the L1 there are many issues that are taken for granted and this is not the case in EMI classes, where the teacher needs to make comprehension checks more regularly...

With regard to change in pedagogy, a Pearson Chi-Square found no statistically significant differences according to whether respondents had or had not taken part in PD, although a significant difference was found for those who replied that they 'were not sure' whether EMI had to change (Pearson Chi-Square $=33.595 ; \mathrm{df}=6 ; \mathrm{p}<.001)$. In other words, it was those respondents that said that they were 'not sure' whether teaching had to change that were also likely to be those who had not undertaken PD.

We asked, in the light of the discussion in our background section, whether a different kind of English proficiency was needed to teach students compared to presenting their subject at a conference. Once again, they overwhelmingly agreed that teaching their students was a very different undertaking (78.2\% agreed; $41 \%$ disagreed; not sure $17.5 \%)$. 
In order to probe further EMI teacher enthusiasm for professional development leading to certification and the competencies that might be obtained we asked a series of questions relating to the amount of learning effort teachers were prepared to expend in order to obtain certification. After all it is easy to say that one would like a certificate of competence, quite another to dedicate time and effort from an already busy teaching (and possibly research) schedule to acquire competence. We first asked how interested EMI teachers were in how people learn English. Our above background section has hinted at the possible importance of what we might call 'applied linguistics knowledge'. Table 4.1 does not show overwhelming enthusiasm for acquiring this competence or attribute. Given that our sample had teachers from a variety of disciplines we were also able to explore if there were differences between these (see Table 4.2). Analysis of variance indeed showed that there were $(\mathrm{F}=3.139 ; \mathrm{df}=5 ; \mathrm{p}<.01)$. A subsequent tukey test demonstrated that the differences all lay between 'humanities with a language focus' and the other disciplines. There were no statistical differences among all the other disciplines. For example, there were no differences between NatSci and SocSci or between MedSci and Hums. We consider this lack of difference to be an important finding which we return to in our discussion.

\section{INSERT TABLE 4.1 ABOUT HERE}

\section{INSERT TABLE 4.2 ABOUT HERE}

Further probing into 'how enthusiastic' EMI teachers were for the effort needed to achieve competence and then certification was operationalised by asking them how interested they were in: research in EMI; in reading a selection of journal articles on the topic; on whether they would be prepared to demonstrate an understanding of what they had read; on whether they would be prepared to be observed teaching in relation to an eventual certification; and on whether they would be willing to take a test of academic English. Table 5 provides the results of this probing. As we can see there was a spread of responses showing 
overall only moderate enthusiasm for research into EMI and willingness to actually spend time reading about research on EMI both of which we would propose would be important for an in-depth understanding of the theoretical issues and empirical findings surrounding EMI introduction and implementation.

\section{INSERT TABLE 5 ABOUT HERE}

The three probing questions relating to personal evaluation are presented in Table 6.1 and Table 6.2. Here there is more enthusiasm, with only some $30 \%$ of respondents reacting negatively to demonstrating an understanding of theory and research, $67.2 \%$ being willing to undertake a test of academic English (but note the considerable percentage for 'not sure'). That less than half (45\%) were willing to be observed in their teaching and $17.25 \%$ feeling 'unsure' about this form of evaluation, however, suggests a possible anxiety which we will return to in our discussion.

\section{INSERT TABLE 6.1 ABOUT HERE}

\section{INSERT TABLE 6.2 ABOUT HERE}

Analysis of the 'open-ended questions' allows us to probe further into teachers' attitudes in this respect. For those more willing to undertake a test of academic English, they were mainly 'motive driven' - for example, out of the desire to become a better teacher. To quote an 'enthusiastic' respondent - 'I would do anything to be a better teacher!'. Those taking a negative or ambivalent position were more concerned with the cost, time, and utility associated with such an examination. For example, a respondent explained in the open-ended section: 'I will take the test if you (can) give me back that time. For example, I will not have time to prepare an $\mathrm{H} 2020$ proposal because I have to prepare the test. However, if you pay the $15 \mathrm{~K}$ that takes to prepare an H2020 proposal I (would then) take the test.' Some respondents expressed their reservations about the utility of the test (and related certification) in terms of benefiting their career development. 
We also investigated whether these questions were differentiated by discipline. An ANOVA with discipline as the independent variable showed that there were significant differences for interest in research $(\mathrm{F}=2.696 ; \mathrm{df}=5 ; \mathrm{p}<.05)$, and in reading a selection of journal articles $(\mathrm{F}=3.623 ; \mathrm{df}=5 ; \mathrm{p}<.01)$. A post-hoc tukey test confirmed that the first difference lay between SocSci and Hums+Lang, with the former being less interested and the second difference lay between Maths and Hums+Lang; NatSci and Hums+Lang; SocSci and Hums+Lang; Hums and Hums+Lang. On the issue of being prepared to read journal articles Hums+Lang teachers were statistically more in favour of doing so. There were no statistical differences among groups for the other questions (understanding what they had read; willingness to take test of academic English; preparedness to be observed teaching). Once again, it was those subjects which already had a strong emphasis on understanding language issues that were most favourable to being evaluated by being observed in the act of teaching. It is possible that having expertise in disciplines with a language focus meant that these respondents had a higher level of English proficiency and were therefore more confident about being observed. Nevertheless the question remains as to how evaluation of an EMI teacher's competence to teach can be achieved without some degree of in-class observation.

When asked what type of PD programme might be appropriate for their institution $51.2 \%$ said that they would prefer a short intensive course with only $28.5 \%$ preferring a course extended over a period of time. We would venture to suggest that the latter type of programme is more expensive in terms of time and resources - experience suggests that short courses are almost invariably held during university vacation time thereby minimising the need for resources to cover absent members of staff. This was confirmed by one respondent who claimed that it depended on 'the programme and the time/period in which it is scheduled'. Another respondent elaborated: ' If the course is taking place within the semester 
it should be extend, BUT my personal opinion is it would better take place outside of the semester/summer time and take 1 week or so.'

The teachers were also given the option of signaling whether they 'would not be willing to take a course' and $9.1 \%$ responded in this way. In order to explore this issue a little further we carried out a Pearson chi-Square to see if those who had declared that they had not yet been involved in any PD were also those that would still not be willing to take the course and we found a statistically significant difference (Chi-Square Value $=18.209$; $\mathrm{df}=8$; $\mathrm{p}<.05)$ : those EMI teachers who had not yet taken part in a development programme were less likely to be willing to take a course of any kind.

\section{SUMMARY OF FINDINGS}

(1) Across a number of countries many EMI teachers are carrying out their profession without having been involved in pre-service or in-service PD with respect to EMI.

(2) Less than a third of respondents stated that their institution provided any kind of certification of competence to teach their subject through the medium of English.

(3) Teachers clearly recognize that EMI requires a greater range of competencies than merely having a threshold level of general English proficiency.

(4) Teachers were overwhelmingly in favour of PD leading to certification and that this certification (acknowledgement of their competencies) would be preferable at an international level. Certification was considered more important by those teachers who had less EMI teaching experience.

(5) However, there was less enthusiasm among teachers for dedicating time and effort to achieving those competencies possibly because of a lack of resources that could be allocated by the institution to achieving competencies leading to certification. 
(6) Some evidence of a preference was detected among teachers (possibly as a consequence of (5) for a short intensive PD course as opposed to a longer more protracted course.

(7) Teachers appeared to experience considerable anxiety at being observed teaching their subject through English.

(8) Surprisingly, there were no obvious differences in teacher attitudes to language learning related issues according to the broad discipline being taught. This is except for those teachers involved in teaching subjects such as Translation and Applied Linguistics; subjects already with a strong language focus.

\section{DISCUSSION}

This study sought to investigate at an international level EMI teacher competence in a rapidly developing situation in which more and more courses are being offered through the medium of an L2 (almost invariably English) in HE. Our data has begun to cast light on the amount of PD undertaken by content teachers currently teaching or about to teach through English, on their attitudes to certification of competencies, on the effort that certification might entail, and on the possible obstacles to certification.

Our findings (from our admittedly limited sample; see 'Limitations' below) suggest that PD for EMI is not a high priority in many HE institutions. This supports earlier findings in studies carried out at the national level (e.g. Cheng 2017). Only a minority of universities offer PD leading to some kind of certification. Given the concern expressed by teachers in previous studies about students' progress (see above), this lack of priority identifies a structural problem.

From our background section we know that independent providers exist but not the extent to which teachers are able to access these providers nor whether there is parity of 
quality and content among the providers. Moreover, the providers whose websites we examined declare a variety of aims and we could detect no clear consensus on what the essential competencies of an EMI teacher might be. From their list of objectives, we might venture to suggest that there is a heavy emphasis on teachers' general English competence rather than the ability to evaluate where students are linguistically and adapt language and pedagogy accordingly as proposed by a number of authors (e.g. Airey, 2011; Vinke, 1995) in order to ensure content learning success. Of course, as pointed out by an anonymous reviewer, from the websites we cannot confidently ascertain that pedagogy is not given a strong focus in the actual programme specifications. Further research is urgently needed regarding this.

The international situation where there is a mixture of local 'in-house' PD and PD provided 'internationally' merits further discussion. Given that the international providers appear to be Anglophone institutions, then it would not be surprising if a great deal of emphasis were being placed on general English language competence. Whether this competence is framed by the 'native speaker model' or a more sophisticated understanding of Global Englishes (Galloway \& Rose 2015) remains to be established. However, the relationship between the local and the global is a tricky one. Our findings suggest that most teachers want a certificate of competence that is recognised at an international level thereby, we assume, enhancing both their own future mobility and that of their students. In the case of the students, an international certificate of their teachers' competence would give greater assurance to any receiving institution (for example for students wishing to study elsewhere at masters or doctoral level). This level of quality assurance would be the case whether students were applying for an Anglophone or non-Anglophone university given the rapid rise of EMI programmes in the latter. However, it would also be pertinent to ask (and indeed research) what local competencies are needed for specific contexts. These might differ according to 
whether the institution was catering for both home and international students or only for the former. If that were the case then principled use of both the L1 and the L2 (Tarnopolsky \& Goodman, 2012) might be a competence that these teachers needed to acquire for certification.

Most of our teacher respondents considered both PD and certification to be important although the envisaged importance of certification declined with experience of teaching through the medium of English. Moreover, it seems that what they envisaged in terms of a PD programme to develop the competencies was a fairly quick fix, something that has not been shown to be particularly efficacious in PD research in general (Burn et al., 2010; Postareff et al., 2008). On the one hand they appeared to hold the belief that enhanced General English proficiency was not enough. On the other they showed little enthusiasm for acquiring the knowledge, understanding and skills that might be required for teaching an academic subject through an L2, competencies that require an underlying shift towards student-centredness and therefore an understanding of SLA issues. We are not of course suggesting that this knowledge and understanding already exists as a result of EMI research, but we would venture that at least some ground-work has been established for that knowledge and understanding in: vocabulary research related to receptive skills (Nation, 2006); in interaction research in SLA (Gass, 1997); and in interaction research related to the teaching of other academic subjects (Mortimer \& Scott, 2003). In other words what might be needed in the toolbox of EMI teacher competence is a merging of subject content knowledge with knowledge about SLA. We would suggest that this knowledge and understanding would also apply to academic subject teachers who are native speakers of English, to teachers who are non-native speakers of English teaching in a context where they do not speak the L1 of the majority of the students, as well as to EMI teachers who share the L1 of their students (those in our study). 
It is of considerable interest that those teachers in our sample who were teaching language-related subjects were keenest to find out about EMI research in general and SLA research in particular. It is also of interest that unlike in previous studies (e.g. Dearden \& Macaro, 2016) we found less of a distinction between science subjects on the one hand and social science and humanities subjects on the other. Put differently, it is perhaps not a universally held belief that in science subjects you can get away with a very limited vocabulary set (direct citation withheld for blinding purposes).

These kinds of competencies, we have begun to propose in this study, need to be identified and developed through observation of teaching (Montgomery, 2002). Yet our findings suggest some reluctance and/or anxiety about observation of teaching being part of the assessment of competence. Iterative observation and feedback (whether by 'experts', peers or line managers) is not only anxiety-inducing but also resources dependent. Institutional recognition is difficult at the best of times (Peat, 2015) and EMI issues make the situation even more complex.

We acknowledge a number of limitations. The number of countries that we were able to survey was limited by the contact methodology that we employed and by our resources. We could have made the survey open to anyone and hoped for respondents from a greater number of countries but we felt that would bring about less reliability of eligible respondents, and indeed the number of respondents we had to eliminate (see methodology above) already suggests that this would have aggravated the problem. However, we feel that we have at least covered four continents albeit selectively. We would welcome future research which uses our survey instrument (available on request) in other countries or jurisdictions. Another limitation resulting from our sample is that we were not able to analyze responses with 'country' as a variable because of the imbalance of numbers from countries. 


\section{CONCLUDING COMMENTS}

EMI programmes in HE have been shown to have a number of problems attached to them.

Yet it is highly likely that they will continue to grow and develop. It is essential that whatever people's misgivings about these programmes might be, teachers, managers and policy makers have a clear understanding from research about the kinds of competencies EMI teachers need. It is also essential that PD programmes are adequately resourced and that EMI teachers are appropriately rewarded for the additional effort involved. One of those rewards, we would suggest, is official recognition through certification.

Acknowledgements (to be completed after blind review process)

We would like to thank the anonymous reviewers for their very helpful suggestions for improving this journal article. 


\section{REFERENCES}

Airey, J. (2011). Talking about teaching in English: Swedish university lecturers' experiences of changing teaching language. Iberica, 22, 35-54.

Ball, P., \& Lindsay, D. (2013). Language demands and support for English-medium instruction in tertiary education: learning from a specific context. In Doiz, Lasagabaster, \& Sierra (Eds.), English-medium universities: global challenges (pp. 44-61). Multilingual Matters.

Borg, S. (2016). English medium instruction in Iraqi Kurdistan. London: British Council. Bradford, A. (2018). It's not all about English! The problem of language foregrounding in English-medium programmes in Japan, Journal of Multilingual and Multicultural Development, DOI: 10.1080/01434632.2018.1551402

British Council/TEPAV. (2015). The State of English in Higher Education in Turkey: A Baseline Study. Ankara: British Council.

Burn, K., Mutton, T., \& Hagger, H. (2010). Strengthening and sustaining professional learning in the second year of teaching.Oxford Review of Education, 36(6), 639-659.

Canagarajah, A. S. (1999). Resisting Linguistic Imperialism in English Teaching. Oxford: Oxford University Press.

Chapple, J. (2014). Finally feasible or fresh façade? Analyzing the internationalization plans of Japanese universities. International Journal of Research Studies in Education, 3(4), 1-14. doi: 10.5861/ijrse.2014.794

Charmaz, K. (2008). Constructionism and the grounded theory method. In J. A. Holstein, \& J. F. Gubrium (Eds.), Handbook of constructionist research (pp. 397-412). New York: The Guilford Press.

Cheng, R. (2017). A sneak peek at training EMI instructors in China. Journal of Immersion and Content-Based Language Education, 5(1), 87-109.

Cho, D. W. (2012). English-medium Instruction in the university context of Korea: Tradeoff between teaching outcomes and media-initiated university ranking. The Journal of Asia TEFL, 9(4), 135-163.

Coleman, J. A. (2006). English-medium teaching in European higher education. Language Teaching, 39(1), 1-14.

Dearden, J. \& Macaro, E. (2016) Higher Education Teachers' Attitudes towards English Medium Instruction: A three country comparison. Studies in Second Language Learning and Teaching. DOI: https://doi.org/10.14746/sllt.2016.6.3.5

Dimova, S., \& Kling, J. (2015). Lecturers' English proficiency and university language policies for Quality Assurance. In R. Wilkinson, \& M. Walsh (Ed.), Integrating content and language in higher education: From theory to practice. Selected papers from the 2013 ICLHE conference (pp. 50-65). Frankfurt am Main: Peter Lang.

Dubow, G., \& Gundermann, S. (2017). Certifying the linguistic and communicative competencies of teachers in English-medium instruction programmes. Language Learning in Higher Education, 7(2), 475-487.

Fenton-Smith, B., Humphries, P., \& Walkinshaw, I. (Eds.). (2017). English Medium Instruction in Higher Education in Asia-Pacific: From Policy to Pedagogy. Dordrecht: Springer-Gardner.

Fortanet-Gómez, I. (2012). Academics’ Beliefs about Language Use and Proficiency in Spanish Multilingual Higher Education. AILA, 25, 48-63.

Galloway, N. \& Rose, H. (2015). Introducing Global Englishes. London: Routledge.

Galloway, N., Kriukow, J., \& Numajiri, T. (2017). Internationalisation, Higher Education and the Growing Demand for English: An Investigation into the English Medium of Instruction (EMI) Movement in China and Japan. The British Council. 
Gass, S. M. (1997). Input, Interaction and the Second Language Learner. Mahwah, NJ: Lawrence Erlbaum Associates.

Gimeno, A. Seiz, R. de Siqueria, J. M. \& Martinez A. (2010) Content and language integrated learning in higher education using the inGenio online multimedia authoring tool. Procedia Social and Behavioural Sciences. 2, 3170-3174

Guarda, M., \& Helm, F. (2016). 'I have discovered new teaching pathways': the link between language shift and teaching practice. International Journal of Bilingual Education and Bilingualism, 20(7), 897-913.

$\mathrm{Hu}, \mathrm{G} .$, \& Li, X. (2017). Asking and answering questions in English-medium instruction classrooms. In Z. Jing, \& L. Q. Dixon (Eds.), English-Medium Instruction in Chinese Universities: Perspectives, discourse and evaluation (pp. 184-203). London: Routledge.

Huang, D. F., \& Singh, M. (2014). Critical perspectives on testing teaching: reframing teacher education for English medium instruction. Asia-Pacific Journal of Teacher Education, 42(4), 363-378.

Jenkins, J. (2014). English as a Lingua Franca in the International University: The politics of academic English language policy. London: Routledge.

Jensen, C., \& Thøgersen, J. (2011). Danish University lecturers' attitudes towards English as the medium of instruction. Ibérica, 22, 13-34.

K, B., \& Botha, W. (2015). English in China's universities: Past and present. World Englishes, 34, 190-214.

Kırkgöz, Y. (2009). Students' and lecturers' perceptions of the effectiveness of foreign language instruction in an English-medium university in Turkey. Teaching in Higher Education, 14(1), 81-93.

Kılıçkaya, F. (2000). Instructors' Attitudes towards English-Medium Instruction in Turkey. Humanizing Language Teaching, 8(6), 1-12.

Kim, E. G., \& Shin, A. (2014). Seeking an Effective Program to Improve Communication Skills of Non-English-Speaking Graduate Engineering Students: The Case of a Korean Engineering School. IEEE Transactions on Professional Communication, 57(1), 41-55.

Kirkpatrick, A., \& Liddicote, A. J. (2017). Language education policy and practice in East Asia and Southeast Asia. Language Teaching, 50(2), 155-188.

Kling, J. M., \& Stæhr, L. S. (2012). The development of the Test of Oral English Proficiency for Academic Staff (TOEPAS). Technical report. Centre for Internationalisation and Parallel Language Use (CIP), ENGEROM, Faculty of Humanities, University of Copenhagen.

Kunioshi, N., \& Nakakoji, H. (2018). Features, challenges and Prospects of a Science and Engineering English-taught program. In A. Bradford, \& H. Brown (Eds.), Englishmedium Instruction in Japanese Higher Education. Bristol: Multilingual Matters.

Lasagabaster, D. (2013). The use of the L1 in CLIL classes: The teachers' perspective. Latin American Journal of Content and Language Integrated Learning, 6(2), 1-21.

Macaro, E. (2018) English Medium Instruction: Language and content in policy and practice. Oxford: Oxford University Press.

Macaro, E. (2018) English Medium Instruction: Language and content in policy and practice. Oxford: Oxford University Press.

Margic, B. D., \& Vodopija-Krstanovic, I. (2017). Uncovering English-Medium Instruction: Glocal Issues in Higher Education. New York: Peter Lang.

Montgomery, D. (2002). Helping teachers develop through classroom observation (2nd ed.). London: David Fulton. 
Mortimer, E. F. \& Scott, P. H. (2003).Meaning making in secondary Science classrooms. Maidenhead: Open University Press.

Nation, I. S. P. (2006). How large a vocabulary is needed for reading and listening? Canadian Modern Language Review, 63, 59-82.

Peat, J. (2015). Getting down to the nitty-gritty: The trials and tribulations of an institutional professional recognition scheme. Perspectives: Policy and practice in higher education, 19, 92-95.

Postareff, L., Lindblom-Ylänne, S., \&Nevgi, A. (2008). A follow-up study of the effect of pedagogical training on teaching in higher education. Higher Education, 56, 29-43.

Rogier, D. (2012). The effects of English-medium instruction on language proficiency of students enrolled in higher education in the UAE (Doctoral dissertation). University of Exeter, United Kingdom. Retrieved from https://ore.exeter.ac.uk/repository/bitstream/handle/10036/4482/RogierD.pdf?sequenc $\underline{\mathrm{e}=2}$

Rose, H., \& McKinley, J. (2018). Japan's English-medium instruction initiatives and the globalization of higher education. Higher Education, 75(1), 111-129.

Sert, N. (2008). The Language of Instruction Dilemma in the Turkish Context. 36(2), 156171.

Tarnopolsky, O., \& Goodman, B. A. (2012). Language practices and attitudes in EFL and English-medium classes at a university in Eastern Ukraine. Working Papers in Educational Linguistics, 27(2), 1-18.

Tigelaar, D. W. \& Van der Vleuten, C. (2004). The development and validation of a framework for teaching competencies in higher education. Higher Education, 48, 253-268.

Tong, F., \& Shi, Q. (2012). Chinese-English bilingual education in China: a case study of college science majors. IJBE\&B, 15(2), 165-182.

Trigwell, K. (2001). Judging university teaching. The International Journal of Acaemic Development, 6/1, 65-73

Vinke, A. A. (1995). English as the medium of instruction in Dutch Engineering education (Doctoral dissertation). Delft University of Technology, the Netherlands. Retrieved from http://repository.tudelft.nl/islandora/object/uuid:491b55f9-fbf9-4650-a44dacb9af8412a8?collection=research.

Wächter, B., \& Maiworm, F. (2014). English-taught programmes in European higher education: The state of play in 2014. Bonn: Lemmens Medien GmbH.

Wilkinson, R., \& Walsh, M. (Eds.). (2013). Integrating content and language in higher education: From theory to practice. Selected papers from the 2013 ICLHE conference. Frankfurt am Main: Peter Lang. 


\section{TABLES}

Table 1. Teachers' participation in pre- or in-service training in EMI.

\begin{tabular}{|c|c|c|c|}
\hline \multicolumn{4}{|c|}{ Question: Have you taken part in any pre- or in-service training in EMI? } \\
\hline & & Frequency & Valid Percent \\
\hline \multirow[t]{3}{*}{ Valid } & No & 283 & 61.4 \\
\hline & Yes & 178 & 38.6 \\
\hline & Total & 461 & 100 \\
\hline Missing & System & 2 & \\
\hline Total & & 463 & \\
\hline
\end{tabular}

Table 2. Teachers' perception of Institutions' offering of Certification to teach EMI.

Question: Does your institution provide any Certification to teach EMI (teachers)

Frequency Valid Percent

\begin{tabular}{lccc} 
Valid & No & 218 & 47.2 \\
& Yes & 108 & 23.4 \\
& Don't know & 136 & 29.4 \\
& Total & 462 & 100 \\
Missing & System & 1 & \\
Total & & 463 & \\
\hline
\end{tabular}


Table 3. Teachers' perceptions of the importance of EMI certification.

\begin{tabular}{|c|c|c|c|c|c|c|c|}
\hline Importance & Not at & Slightly & Moderatel & Very & Extremel & Total & Missin \\
\hline of & all & important & $\mathrm{y}$ & important & $\mathrm{y}$ & (Valid & g \\
\hline certificatio & importan & & important & & important & ) & \\
\hline $\mathrm{n}$ & $\mathrm{t}$ & & & & & & \\
\hline For you & $43(10 \%)$ & $47(10.9 \%$ & $129(29.9 \%$ & $143(33.2)$ & $69(16.0 \%$ & 431 & 32 \\
\hline personally & & ) & ) & & ) & & \\
\hline For your & $31(7.2 \%$ & $46(10.7 \%$ & $133(31.1 \%$ & $157(36.7 \%$ & $61(14.3 \%$ & 428 & 35 \\
\hline subject & ) & ) & ) & ) & ) & & \\
\hline \multicolumn{8}{|l|}{ Departmen } \\
\hline \multicolumn{8}{|l|}{$\mathrm{t}$} \\
\hline For your & $17(4.0 \%$ & $41(9.6 \%)$ & $104(24.4 \%$ & $169(39.6 \%$ & $96(22.5 \%$ & 427 & 36 \\
\hline institution & ) & & ) & ) & ) & & \\
\hline \multirow[t]{2}{*}{ Globally } & $17(4.0 \%$ & $28(6.5 \%)$ & $131(30.6 \%$ & $179(41.8 \%$ & $73(17.1 \%$ & 428 & 35 \\
\hline & ) & & ) & ) & ) & & \\
\hline
\end{tabular}

Question: How interested are you in how people learn English (teachers)?

Note. The number in each column represents 'Frequency' and the percentage refers to 'Valid Percent'.

Table 4.1. Teachers' interest in understanding how people learn English. 


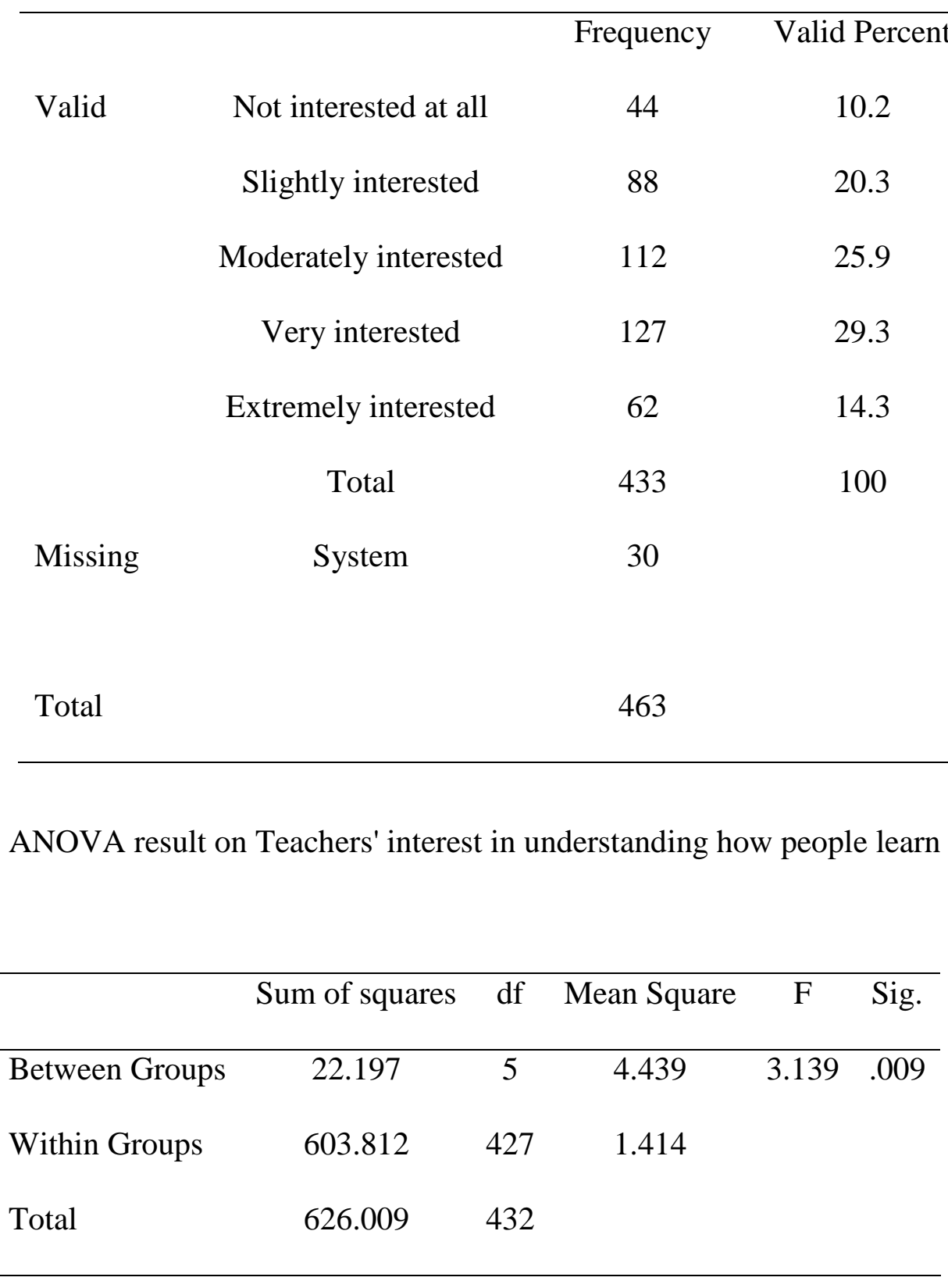

Table 4.2.

ANOVA result on Teachers' interest in understanding how people learn English.

Table 5. Teachers' interest in activities related to EMI.

\begin{tabular}{lccccccc}
\hline Level of & Not at all & Slightly & Moderately & Very & Extremely & Total & Missin \\
interest & interested & intereste & interested & interested & interested & (Valid & $\mathrm{g}$ \\
& & $\mathrm{d}$ & & & & & \\
& & & & & & & \\
\hline In & $45(10.4 \%$ & $81(4.6 \%)$ & $132(18.8 \%$ & $115(30.6 \%$ & $59(26.6 \%$ & 432 & 31 \\
research & ) & & & & & & \\
\end{tabular}


into

EMI

$\begin{array}{llllllll}\text { In } & 56(1.2 \%) & 73(5.8 \%) & 130(16.3 \% & 121(48.8 \% & 53(27.9 \% & 433 & 30\end{array}$

reading

selectio

$\mathrm{n}$ of

journal

articles

on EMI

Table 6.1 Teachers' interest in demonstrating understanding of what they have read

\begin{tabular}{|c|c|c|c|c|c|c|c|}
\hline $\begin{array}{l}\text { Level } \\
\text { of }\end{array}$ & $\begin{array}{l}\text { Not at all } \\
\text { interested }\end{array}$ & $\begin{array}{c}\text { Slightly } \\
\text { interested }\end{array}$ & $\begin{array}{l}\text { Moderately } \\
\text { interested }\end{array}$ & $\begin{array}{c}\text { Very } \\
\text { interested }\end{array}$ & $\begin{array}{l}\text { Extremely } \\
\text { interested }\end{array}$ & $\begin{array}{l}\text { Total } \\
\text { (Valid }\end{array}$ & $\begin{array}{c}\text { Missin } \\
\mathrm{g}\end{array}$ \\
\hline interest & & & & & & ) & \\
\hline In & $64(14.9 \%$ & $63(14.7 \%$ & $129(30.1 \%$ & $126(29.4 \%$ & $47(11.0 \%$ & 429 & 34 \\
\hline researc & ) & ) & ) & ) & ) & & \\
\hline
\end{tabular}


$\mathrm{h}$ into

EMI

Table 6.2 Teachers' interest in taking English test and observed with certification as outcome

No $\quad$ Yes $\quad$ Not sure $\quad$ Total Missing

(Valid)

Willing to take test of

$63(13.8 \%) \quad 307(67.2 \%) \quad 87(19.0 \%)$

457

6

academic and non-academic

English

$\begin{array}{llll}\text { Be prepared to be observed } \quad 165(36.7 \%) & 206(45.8 \%) & 79(17.5 \%)\end{array}$ 13

with certification as outcome 